\title{
Correction to: NADPH Oxidases in Inflammatory Bowel Disease
}

\section{Emily Stenke, Billy Bourke, and Ulla G. Knaus}

\section{Correction to:}

Chapter 38 in: Ulla G. Knaus and Thomas L. Leto (eds.), NADPH Oxidases:

Methods and Protocols, Methods in Molecular Biology, vol. 1982,

https://doi.org/10.1007/978-1-4939-9424-3_38

The title of Chapter 38 was published with a typo error. It should read "NADPH Oxidases in Inflammatory Bowel Disease", whereas the title was mistakenly printed as "NAPDH Oxidases in Inflammatory Bowel Disease" and the book has been updated for this error.

The updated online version of this chapter can be found at https://doi.org/10.1007/978-1-4939-9424-3_38 